\title{
The Ending of Great Expectations According to South Park: A Science- Fictional Revisitation
}

\section{Introduction}

The South Park episode dedicated to Great Expectations by Charles Dickens - aired in the United States on TV-MA on November 29, 2000 - is the nineteenth adaptation of this literary classic if we take into consideration only cinematographic, televised, and animated versions (see Bolton 1987; Glavin 2003; McFarlane 2008; Hammond 2015).

The consistent attention of adaptors and rewriters in the last century undoubtedly testifies to the novel's immortality and its constant actuality, further confirmed by the continuous publication in the last ten years of fanfictions, crossovers, and the experimental Twitterature retelling by Aciman and Rensin. ${ }^{1}$ What these works have in common, according to a postmodern trend, is often the aim to rewrite the destiny of some characters or add new episodes absent in the original plot, or - varying the setting and the original characters - to emphasize a main theme and modernize the hypotext, the characters, and the value-system, showing the vitality of the original story transposed into a new context and in the contemporary era (see Doležel 1999: 201-227).

The link between these works and the South Park episode is clear not only because of the ironic and parodic tones which characterize them, but also because of the intention to modernize the Dickensian novel and, as we will see, to highlight a theme with the aim of refunctionalizing it.

Referring to South Park it is important to remember that, in keeping with the most recurrent themes of the animated series - known to be inclined to the most pressing and controversial aspects of contemporary

${ }^{1}$ For an overview on literary and digital rewritings see Cao "The Fortune of Great Expectations from the Nineties to Today" and Le riscritture di Great Expectations. 
society and particularly attentive to minorities - Pip had already been featured in a number of episodes of South Park, embodying the stereotype of the unfortunate orphan abused by adults and peers, just as in the original text. Having reached the fourth season of the series, the producers decided to interrupt the regular transmission of the episodes to show the "true story" of this character.

The decision to suspend the regular flow of a popular animated series in order to devote a whole episode to a literary work could not be accidental. The term "break" is indeed used by the actor Malcolm McDowell, the storyteller who introduces the episode: the declared intention of the episode, as he says, is «to take a break from their regular show» to tell the complete story of this book from the beginning to the end as his young and ignorant audience learn more about this masterpiece of English literature. As Sconce underlines in his article on two adaptations of Dickens novels, the use of the term "break" is particularly interesting because

series television is structured by what various critics have described as a tension between repetition and difference. All popular series in any medium, indeed, must balance repetition of successful (i.e. commercial) story elements with a search for forms of difference that will provide novel variation and interest. Such balance, crucial in all popular genres, is especially important in television where a series may run for hundreds of episodes and depends on predictable, cyclical consumption. (Sconce 2003: 184)

Therefore, pleasing the audience requires striking the proper balance between tried-and-true foundational formulas and moments of improvisation: in this case the element of "improvisation" is the choice of an episode that deviates from the conventional setting and characters of South Park, but at the same time we can also recognize important elements of continuity between the Dickensian poetics and that of the animated series. There are indeed two interesting aspects that link Dickens to the "poetics" of this series: first of all, the penchant for class satire, and second, the incredible variety of colliding and conflicting discourses woven together to create his prose (the "heteroglossia" so celebrated in Dickens by Bakhtin).

Starting from the predominant role of the heteroglossia, both in Dickens and in the South Park episode, the following analysis aims to demonstrate how the science-fictional rereading of this Dickensian novel modernizes the story through the use of multiple languages, and takes to the extreme a focal point, mostly neglected by other transpositions and rewritings of this classic: the theme of doubles and alienation, in particular with regard to Estella and Miss Havisham. 


\section{The Transposition}

As an intersemiotic translation, the adaptation implies a relationship with the source text on two different levels: primarily in terms of semiotic code switching - with all the various solutions that the difference between the two semiotic systems implies (in this case the use of cuts, condensations, displacements and voice over) (see Corrigan 1999; Cortellazzo and Tommasi 1988; Eco 2010; Kozloff 1988; McCabe et al. 2011) - and, to a lesser extent, in terms of systems of signification. ${ }^{2}$

In regard to this second point, it should be noted that each translation is first and foremost an act of interpretation, a dialogue between the target text and the source text: as Lotman emphasizes, in order the text to be an active device, it needs to be inserted in a chain of communication "so that it begins to operate as a generator of new texts and messages" (Lotman 1982: 8).

Moreover, these two levels of analysis are strictly related and they cannot be considered separately: every artistic text, like a "musical score" (Barthes 1973: 28) offers interpretative paths that the target text thus transforms "according to the strategies and translation techniques one choses to adopt, and more so when translating from single-medium texts to syncretic texts, which are inevitably different from the source text even in the construction of meaning effects" (Dusi 2010: 90).

A comparative analysis of the South Park episode, therefore, allows us to illustrate the translation strategies adopted by the target text in relation to the source text, and also to show how the adaptation, as a "form of active reworking" (Doležel 1999: 216), "opens up and multiplies the source text [and], can "re-semanticize" it, making us rediscover it through its new interpretation" (Dusi 2010: 92).

Since every transposition is firstly an interpretative act, it should be examined not only as a product readable exclusively in relation to the intention of the source text, but also as a process that adopts a number of translation strategies to "carry a communicative intention that can be identified through textual analysis" (Dusi 2010: 89). At the same time, considering adaptation as an act during which something remains invariant in the transformation of the source text in another semiotic system, a comparative analysis should also explicate the rules of similarity (or equivalence) relevant in the examination of the translation strategies. To this regard, as we will see, the interpretation of Great Expectations conveyed by the South Park episode emerges from the cooperation of the

${ }^{2}$ See Dusi 2010. Where the text adopted is in Italian, the translation is mine - C.C. 
different languages used by the transposition: first of all the role of the narrator (as a voice over); the use of cuts and condensations; the dialectic between parodic and faithful parts; and the shift of genre in the last part.

\section{Double and Alienation in Great Expectations}

Due to the complexity of the plot, rich in characters with their respective stories and subplots, I am only going to take account of the macrostructure of the novel in order to illustrate, subsequently, the themes of the double and the alienation in Great Expectations.

It should be remembered that the Dickensian novel is divided into three parts. The first one is about Pip's childhood, when he meets the convict Magwitch at the graveyard and then Miss Havisham and Estella at Satis House; in the second part he leaves his sister's house to go to London, where he is educated as a gentleman as decided for him by his anonymous benefactor; finally, in the third part, Pip discovers that his putative father is the convict met years before at the graveyard, so he loses his fortune and, at the same time, even his beloved Estella, who marries a rude man named Bentley Drummle. As is known, Great Expectations does not have a univocal ending, because of the author's choice to erase the first unhappy conclusion to meet the expectations of the greatest part of his readers. ${ }^{3}$ However, what is important about both endings is the death of Drummle, the reconciliation between Estella and Pip and, in the definitive published version, the ambiguous allusion to the possibility of a marriage between them.

Even if this brief summary cannot demonstrate the richness of themes and issues of this novel, Great Expectations is an unconventional Bildungsroman that creates at least two thematic levels. At the first level we find the theme of the power of money and the rise and the fall of a poor orphan: at this level, as Peter Brooks has observed, we can also recognize the motives of the repetition (in terms of return and regression of the main character), the passivity of this anti-hero under Magwitch and Miss Havisham's will, and the social regression of Pip and Estella as a consequence of their passivity. At the second semantic level, but strictly related to the first one, we find the theme of doubles: first, since his childhood the relationship between Pip and his family is characterized by the obligation of the orphan to repeat his brother-in-law's destiny. Pip is

${ }^{3}$ See Dickens 1996: 440-441. The edition by Carlisle is the same used for the quotations. 
destined to become a forger just like Joe and he has no alternatives for his future because he lacks a "true family" (see Sadrin 2010: 95-111). Second, his love for Estella brings him to a desire for change in a socioeconomic sense, as he wants to follow the model of the perfect gentleman to acquire Estella's love. Third, his relationship with the putative father is based on Magwitch's desire to transform Pip into a gentleman out of a sense of revenge against the English bourgeoisie that has excluded him from society, condemning him to deportation in Australia. Last, Pip's story is doubled in Estella's life: her relationship with Miss Havisham is marked by the desire of the old lady to transform her stepdaughter into an instrument of revenge against the male sex. ${ }^{4}$

It is this strict relationship between these two thematic levels that I intend to examine in order to highlight the intertextual dynamics put in place by the South Park episode in comparison with the Dickensian novel. In Great Expectations the passivity of the two main characters - passivity, as we will see, soon turned into alienation - is strictly related to the role of the two step-parents - respectively Magwitch and Miss Havisham who transform the two young characters into their "creatures", into their doubles, as a means of revenge. However, whereas the greatest part of the transpositions and the rewritings have emphasized the sentimental relationship between Pip and Estella and Pip's social ascent, this animated series, even if in a parodic form, for the first time focuses on Estella's story, on the role of Miss Havisham's room as the driving force behind the alienation of Estella and on the evolution of the young lady, confirmed by the two versions of the Dickensian ending.

Effectively, despite the chronological limits of the episode (only twenty-one minutes) all three parts of the original work are recognizable and what is noticeable at first sight is the secondariness of Pip's social ascent, while Miss Havisham and her relationship with Estella are placed in the foreground. However, since about eight minutes of the episode are dedicated to each part of the novel, only in the last eight minutes are the themes of the double and the passivity of the two characters modernized and refunctionalized in a science-fictional rereading.

To understand this refunctionalization of the roles of Miss Havisham and the Satis House rooms in the transposition, it is first necessary to come back to the role played by these elements in the source text, in order to illustrate how the science-fictional revisitation is pertinent and coherent with the inferences suggested by the source text:

${ }^{4}$ On the theme of the double in Great Expectations see Frye and the psychoanalytic analysis of Great Expectations collected by Rosenberg, Carlisle, Marroni. 
No glimpse of daylight was to be seen in it. It was a dressing-room as I supposed from the furniture, though much of it was of form and uses then quite unknown to me. But prominent in it was a draped table with a gilded looking-glass, and that I made out at first sight to be a fine lady's dressing-table. [...] She was dressed in rich materials - satins, and lace, and silks - all of white. Her shoes were white. And she had a long white veil dependent from her hair, and she had bridal flowers in her hair, but her hair was white. Some bright jewels sparkled on her neck and on her hands, and some other jewels lay sparkling on the table [...].I saw that everything within my view which ought to be white, had been white long ago, and had lost its luster, and was faded and yellow. I saw that the bride within the bridal dress had withered like the dress, and like the flowers, and had no brightness left but the brightness of her sunken eyes. (Great Expectations, Dickens 1996: 70-71)

Miss Havisham's room, where the clocks have been stopped in the attempt to control and deny the natural course of the time in order to obliterate the trauma of the abandonment before the wedding, is a room where the absence of life is reflected in the attempt to refuse the existence of time. This is enhanced by the insistence on the colour white of the objects, of the powder and the wedding dress that gradually extends up to the figure of the lady, gradually assimilated to the inorganic condition of her room. As Massimo Fusillo observes (see Fusillo 2011: 47-53), at Satis House the objects contaminate the human beings and assimilate them to inanimate beings.

It is possible to find the evidence of Miss Havisham's regression to a state of pure matter from the first words addressed to Pip, during the visit of the young boy at Satis House:

"What do I touch?"

"Your heart".

"Broken!"

She uttered the word with an eager look, and with strong emphasis, and with a weird smile that had a kind of boast in it. (Great Expectations, Dickens 1996: 72)

The role of the old lady and her house as emblems of the assimilation of human beings to the inorganic condition is confirmed by their effects on Miss Havisham's double, Estella, who shortly after tells Pip that she was deprived, as her stepmother before her, of the element conventionally symbolic of feelings: the heart.

"You must know", said Estella, condescending to me as a brilliant and beautiful woman might, "that I have no heart - if that has anything to do with my memory" [...]. "Oh I have no heart to be stabbed in or shot in, I have no doubt", said Estella, "and of course, if it ceased to beat I should cease to be. But you know what I mean. I have no softness there, no - sympathy - sentiment - nonsense". (Great Expectations,

Dickens 1996: 226-227) 
The regressive path made by Estella towards the inorganic condition, contaminated and absorbed by Miss Havisham's underworld, is sanctioned by the words addressed to Pip during one of their meetings in London, which confirm their transformation into true inanimate tools in Miss Havisham's hands:

\footnotetext{
"Now", said Estella, gliding away the instant I touched her cheek, "you are to take care that I have some tea, and you are to take me to Richmond".

Her reverting to this tone as if our association were forced upon us and we were mere puppets, gave me pain; but everything in our intercourse did give me pain. (Great Expectations, Dickens 1996: 253) ${ }^{5}$
}

This reference to puppets acquires important connotations not only as a proof of the reification of the human beings inside Miss Havisham's rooms, but also as a confirmation of the importance of the manipulation of the two younger characters in this novel.

The two themes of the duplication and the passivity of Estella, up to her alienation from the human condition, already have had a great importance in the Dickensian narration, as observed by Alessandro Monti in his introduction to the Italian version of Great Expectations:

the rooms in which the old lady lives sequestered can be seen as a laboratory [...] a pre-futuristic place of biologic manipulation. Pip (and before him Estella) are objects of an experiment; in the case of the young boy, the animal condition of the first chapters evolves into that of guinea-pig. Estella is instead transformed into an alien creature, without normal emotive and affective instincts [...] she is implicitly a mutant, a creature not of our evolutionary moral dimension (not surprisingly compared, because of her name, to the stars and to their light, far away and without any warmth). (Monti 1996: xxv-xxvi) ${ }^{6}$

Before concluding with the analysis of these themes in Great Expectations, we have to underline that one of the main consequences of the transformation of Estella into a sort of clone of Miss Havisham's inhumanity is the duplication of the traumatic scene of Miss Havisham's abandonment, as we notice in the old lady's reaction to Estella's thanklessness:

“You stock and stone!" exclaimed Miss Havisham. "You cold, cold heart!" "What?" said Estella, preserving her attitude of indifferences as she leaned against the great chimney-piece and only moving her eyes; "do you reproach me for being cold? You?" [...] "You should know", said Estella. "I am what you have made me. Take all the praise, take all the blame; take all the success, take all the failure; in short, take

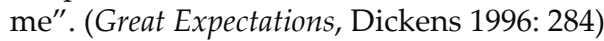

\footnotetext{
${ }^{5}$ Italics is mine - C.C.

${ }^{6}$ Translation is mine-C.C.
} 
The repetition of the episode of Miss Havisham's abandonment this time experienced through Estella - and the definitive failure of the experiments on Estella's life breaks the spell of those rooms and the figure of Miss Havisham no longer has a reason to exist. The fire, the destruction of the artificial environment that the old lady had created as a denial of the life itself, is the only possible outcome and only after the spell is broken can both Miss Havisham and Estella fully realize the consequences of their past actions: Miss Havisham confirms her awareness by asking for forgiveness on her deathbed, and in Estella's case, only after the liberation from her stepmother's influence it is possible to have a reconciliation with Pip (as suggested by both endings).

As we are going to see shortly, the science-fictional revisitation produced by South Park emphasizes all these aspects of the original story, focusing on the process of alienation and liberation of Estella in contrast to her stepmother. ${ }^{7}$

\section{The South Park Episode}

Keeping in mind the two semantic levels in Great Expectations, I am going to focus on the translation strategies adopted by the South Park episode to foreground the theme of the double in the transposition of the novel in a science-fictional version. If the adaptation as a syncretic text uses multiple languages to convey its communicative intention, in this case we notice that the four main means used by this transposition are the presence and the function of the storyteller, the use of cuts and condensations, the dialectic between parody and fidelity and, finally, the shift of genre.

The main strategy adopted to allow a transposition of a work such as Great Expectations in so brief an episode is the presence of the storyteller. The twenty-one minutes of the episode are indeed spaced out by seven interventions of the narrator: for all of the interventions the scene moves into the living room where sitting in an armchair with the open book, we find the actor Malcolm McDowell, who gives the audience explanations about the events cut from the original plot. At first glance it might seem that the function of these interventions is either ironic - since they want

${ }^{7}$ In this case the science-fictional turn of the story is given by the new and unexpected role played by high technology and scientific experiments in Miss Havisham's attempt to change the destiny of Dickensian characters. 
to remind us of the ironic role of the storyteller in the first chapters of the Dickensian text, showing the contradiction between the impressions of the young protagonist and the reality of facts - or that they are simply allusive to the intrusiveness of the omniscient narrator in the original story: well-known indeed are the narrator's "prolepsis" (Genette 1980: 40) and his intrusive moral remarks in Great Expectations. However, upon closer examination, it emerges that the effect obtained by the presence of the storyteller is to highlight the true core of the story that South Park has chosen as its focal point: the relationship between Miss Havisham and Estella. Without the many interventions of the narrator, who summarizes the events that do not relate to the two ladies, it would not be possible to keep the focus mainly on their story in the conventionally brief duration of the episode, given the complexity of the whole plot.

However, the interventions of the narrator are only the first of the many translation strategies of the transposition to convey its communicative intention. Strictly related to them are two further elements: cuts and condensations. In this regard, we should specify that some characters of the source text (with the respective subplots) have been suppressed: Wopsle and Pumblechoock, Orlick and Biddy, Compeyson and his relationship with Miss Havisham and Magwitch. Even if, as McFarlane states, they are the same characters normally eliminated for reasons of duration in longer transpositions, too - as in the cinematographic one - we have to specify that normally at least one or more of them are maintained for their semantic function in the story: they should highlight the centrality of Pip's story because the comparison with them allows the audience to focus on his evolution and on the moral taught by his story. The elimination of all of them together is a confirmation of the centrality acquired by another narrative strand of the source text as well as of the denial of Pip's centrality.

A clearer hint as to the purpose of the cuts and condensations is given by the duration of the original scenes re-proposed in the adaptation and, in particular, by the dialectic between parodic scenes and the ones that are faithful to the source text. A confirmation of the secondariness of the theme of Pip's social ascent is given by the overall duration of just two minutes of the two scenes where - at the beginning and at the end of the story - Pip and Magwitch are protagonists (their first encounter at the graveyard and their final reconciliation).

The same can be said for the brevity of the scenes dedicated to Pip's education in London as a gentleman, mostly summarized by the narrator, while the only moment to which more attention is given is when Herbert tells Miss Havisham's story to Pip during their first dinner in London. 
Not only the brevity of the scenes dedicated to these parts or the interventions of the narrator, but also the skilful alternation between parodic scenes and faithful one confirm the secondariness of the rise and fall of Pip and his love story with Estella: in the first fifteen minutes, the love story between Pip and Estella and Pip's education are transposed in a parodic form, whereas the main events regarding Miss Havisham's attempt to catch Pip and Estella in her trap are transposed accurately, reconfirming the focal function of this narrative core in the adaptation.

In this case, it is the dialogues which communicate the higher or lower level of fidelity. When Pip and Estella are the protagonists - during their first encounter, or during their walk through the garden, or at the dance party in the English "king" Tony Blair's house - dialogues are indeed characterized by a parodic tone: they are not only modernized by the use of anachronistic references and by the choice of the words used - very far from the Dickensian one - but the obscenity of the dialogues and events are also taken to the extreme. We can consider, for example, the moment in which Estella tells Pip that she has a boyfriend, Steve (the equivalent of Bentley Drummle), and she underlines that "he is seventeen and he has a car" or the number of insults that she constantly addresses to Pip. The effect of these choices is clearly the transformation of Pip into a caricature of himself, since his passivity before the young girl is emphasized.

On the contrary, in the first two-thirds of the transposition, the only faithful moments to Dickensian dialogues and atmospheres are those which show Miss Havisham in the darkness of her dining room at Satis House. The attention for her manipulative role, first in relation to Pip and then to Estella, is stressed by the choice of reporting faithfully the first words addressed to the two young characters:

Miss Havisham: "Sometimes I have sick fancies. And I have a fancy I shall like to see someone play. So play. Play. Estella play with this boy".

Estella: "But he is just a commoner".

Miss Havisham: "But you can break his heart".

Estella: "All right, boy, let us play".

The same attention for the old lady is confirmed few minutes later by the choice to refer to her attempt to convince Pip to love Estella:

Miss Havisham: “Oh, you love her don't you, Pip?"

Pip: "I don't know. I mean, I think about her every day".

Miss Havisham: "Do you know what love is, Pip? It is blind devotion, unquestioning self-humiliation, utter submission. Trust and believe against yourself and against the whole world. Giving up your whole heart and soul. Love her, Pip. I developed her into what she is so that she might $[\ldots]$ be loved [...]. Go and seek her out and love her, 
love her. [...] If she wounds you, love her. If she tears your heart into pieces - and as you get older it will tear deeper - love her!"

The fidelity with which these dialogues are quoted in the adaptation is also important for the centrality acquired from this moment by the motif of the "broken heart", repeated several times in the next seven minutes of the episode. The ending of the episode demonstrates that in the passage from the hypotext to the transposition this motif becomes a symbol of the alienation and passivity of the two young characters. The last part is indeed the moment in which the parodic, modernizing and the condensing strategies are taken to the extreme: as in the source text, the trap set by Miss Havisham for Pip emerges with the discovery of the engagement of Estella and Steve. Now, in accord with the modernizing and parodic intentions of the transposition revealed in the previous two parts, the adaptation foregrounds the manipulative role of Miss Havisham.

Miss Havisham: “Things aren't always what they seem, Pip. Oh, what's the matter? Did she... break your heart?"

Pip: "Well... I suppose that if you set out to break my heart, you did a very good job of it... Because it certainly does hurt".

Miss Havisham: "Yes! Tell me about the pain!"

[...]

Pip: "But why do you make your daughter hurt people?"

Miss Havisham: "Why? Well, that's simple. Because I need the tears of broken hearted men to use in my 'Genesis' device. You see, my foolish child, I am growing very old. But tonight, I will fuse my soul into Estella's once and for all. And then I can go on breaking men's hearts for another entire generation!!! [...] Estella, prepare yourself for the Genesis platform. [...] And as for you, Pip, my robot monkeys should take care of you".

Her attempt to control time - which in the source text was expressed by the stopped clocks - is now transposed into an attempt to halt her aging by her fusion with Estella, and the elimination of the young lady's agency is therefore transposed into the definitive cancellation of her existence in favour of Miss Havisham's eternal youth. Her control over the girl, who is already reduced in the source text to a puppet in her hands, is translated here to an explicit transformation of Estella into a guinea pig: her alienation and reduction to an inorganic element, are now necessary for Miss Havisham's experiment. The original role of Pip as a guinea pig and the motif of revenge against the human race are reflected now in her need for the tears of men, Estella's victims, to operate the Genesis device that will finally merge the souls of the two ladies.

In the science-fictional re-reading of the third part of the Dickensian novel, the themes of the duplication, alienation, revenge, and the passivity 
of Pip and Estella in Miss Havisham's hands therefore return with new functions. The change from the Bildungsroman to the science-fiction story in the third part of the episode is understandable only if put in relation to the other means used by the intersemiotic translation to convey its communicative intention. The focus of this adaptation has ceased to be Pip and the moral teaching of his story of rise and fall: the focal point recognized by the adaptors of South Park is occupied by Miss Havisham and Satis House as a place of manipulation and transformation of human into inhuman.

The change of genre grounds these issues in a parodic and modernizing form, but maintains some elements invariant with respect to the source text, remaining faithful to the intention of the original work: as a place of experimentation, Satis House was destined to be destroyed in a fire shortly after Estella's rebellion. Therefore, the ending of the animated series, which shows Estella as the means through which Miss Havisham can achieve her ultimate goal of control of time and life - a clearly extreme version of the original motif of the stopped clocks - expresses the close link between the rebellion of Estella's adoptive mother and the destruction of Satis House through the image of Miss Havisham going up in flames at the exact moment when Estella leaves the Genesis device.

A final mention should be reserved for the original endings: coherently with both Dickensian endings, even the South Park episode shows the possibility of a total liberation of Estella from the influence of Miss Havisham and the possibility of a union between Pip and Estella, but only after the death of the old lady. After that moment, Estella can discover that she has a heart, forsaking her unnatural state as an alien creature, or even as inorganic matter such as a stone or a puppet, to which the manipulation of Miss Havisham had led her.

\section{References}

Bakhtin, Mikhail M. (2004). The Dialogic Imagination: Four Essays. Ed. Michael Holquist. Austin: University of Texas Press.

Barthes, Roland (1973). S/Z. Torino: Einaudi.

Bolton, Philip H. (1987). Dickens Dramatized. Boston: G. K. Hall.

Brooks, Peter (1984). Reading for the Plot. Design and Intention in Narrative. New York: Knopf. 
Cao, Claudia (2015). "The Fortune of Great Expectations from the Nineties to Today". In: Victorianomania. Reimagining, Refashioning, and Rewriting Victorian Literature and Culture. Eds. Simonetta Falchi, Greta Perletti and María Isabel Romero Ruiz. (109-127). Milano: FrancoAngeli.

Cao, Claudia (2016). Le riscritture di Great Expectations. Sei letture del classico dickensiano. Milano-Udine: Mimesis.

Corrigan, Timothy (1999). Film and Literature: An Introduction and Reader. Upper Saddle River: Prentice-Hall.

Cortellazzo, Sara, Dario Tommasi (1988). Letteratura e cinema. Roma-Bari: Laterza.

Dickens, Charles (1996). "Great Expectations". In: Great Expectations. Complete Authoritative Text with Biographical and Historical Contexts, Critical History, and Essays from Five Contemporary Critical Perspectives. Ed. Janice Carlisle. Boston: Bedford Books of St. Martin's Press.

Doležel, Lubomír (1999). Heterocosmica. Fiction e mondi possibili. Trans. M. Botto. Milano: Bompiani.

Dusi, Nicola (2003). Il cinema come traduzione. Da un medium all'altro: letteratura, cinema, pittura. Torino: Utet.

Dusi, Nicola (2010). “Translating, Adapting, Transposing". Applied Semiotics 24: 82-94 [accessed Feb. 22, 2014].

Eco, Umberto (2010). Dire quasi la stessa. Esperienze di traduzione. Milano: Bompiani. Frye, Northrop (1968). "Dickens and the Comedy of the Humours". In: Experience in the Novel. Selected Papers from the English Institute. Ed. Roy Harvey Pearce. (49-81). New York: Columbia University Press.

Fusillo, Massimo (2011). Feticci. Letteratura, cinema, arti visive. Bologna: Il Mulino.

Genette, Gerard (1980). Narrative Discourse: An Essay in Method. Ithaca: Cornell University Press.

Glavin, John (ed.) (2003). Dickens on Screen. Cambridge: Cambridge University Press.

Hammond, Mary (2015). Charles Dickens's Great Expectations. A Cultural Life, 1860 2012. Farnham-Burlington: Ashgate.

Kozloff, Sarah (1988). Invisible Storytellers. Voice-over Narration in American Fiction Film. London: University of California Press.

Lotman, Jurij M. (1982). "Il cervello, il testo, la cultura, l'intelletto artificiale". Intersezioni 2 (1): 5-16.

Marroni, Francesco (ed.) (2006). Great Expectations. Nel laboratorio di Charles Dickens. Roma: Aracne.

McCabe, Colin, Kathleen Murray, and Rick Warner (2011). True to the Spirit. Film Adaptation and the Question of Fidelity. Oxford: Oxford University Press.

McFarlane, Brian (2008). Screen Adaptations. Great Expectations: A Close Study of the Relationship Between Text and Film. London: Methuen.

Monti, Alessandro (1996). "Introduction". Great Expectations. By Charles Dickens. (v-xxxiv). Milano: Mondadori.

"Pip" (2000). South Park. Created by Matt Stone and Trey Parker, performance by Malcolm McDowell. Season 4, episode 14. South Park Digital Studios, LLC, 2000. 
Rosenberg, Edgar (ed.) (1999). Great Expectations. Authoritative Text. Backgrounds. Contexts. Criticism. New York: Norton and Company.

Sadrin, Anny (2010). Parentage and Inheritance in the Novels of Charles Dickens. Cambridge: Cambridge University Press.

Sconce, Jeffrey (2003). "Dickens, Selznick, and Southpark". In: Dickens on Screen. Ed. John Glavin. (171-187). Cambridge: Cambridge University Press. 